\title{
Processos produtivos de trabalhadores rurais no extrativismo da palha de carnaúba
}

\author{
Productive processes of rural workers in the extrativism of the carnaúba straw \\ Procesos productivos de los trabajadores rurales en la extracción de la hoja de \\ carnauba
}

\author{
Francisco Rosemiro Guimarães Ximenes Neto ${ }^{1}$ \\ Francisca Sandra da Ponte Crispim ${ }^{1}$ \\ Petrônio Emanuel Timbó Braga ${ }^{1}$
}

Recebido em 13/03/2018; revisado e aprovado em 06/06/2018; aceito em 17/06/2018

DOI: http://dx.doi.org/10.20435/inter.v20i4.1880

\begin{abstract}
Resumo: O estudo objetivou cartografar o processo produtivo dos trabalhadores rurais no extrativismo da palha de carnaúba. Pesquisa descritiva, do tipo estudo de caso, desenvolvida em Cariré - Ceará, entre maio de 2016 e junho de 2017, com 18 trabalhadores rurais. O extrativismo da palha envolve corte, manuseio de animais, armazenamento inadequado, entre outros, que podem influir diretamente no processo saúdedoença-cuidado-trabalho.
\end{abstract}

Palavras-chave: população rural; trabalho; desenvolvimento rural.

Abstract: The study aimed to map the productive process of the rural workers in the extractivism of the carnauba straw. Descriptive research, of the type of case study, developed in Cariré - Ceará, between May of 2016 to June of 2017, with 18 rural workers. The extrativism of the straw involves cutting, animal handling, inadequate storage, among others, that can directly influence the health-disease-care-work process.

Keywords: rural population; work; rural development.

Resumen: El estudio tuvo como objetivo cartografiar el proceso productivo de los trabajadores rurales en la extracción de la hoja de carnauba. Investigación descriptiva, del tipo estudio de caso, desarrollada en Cariré - Ceará, entre mayo de 2016 junio de 2017, con 18 trabajadores rurales. El extractivismo de la hoja conlleva el corte, el manejo de animales y el almacenamiento inadecuado, entre otras cosas que pueden influir directamente en el proceso salud-enfermedad-cuidado-trabajo.

Palabras claves: población rural; trabajo; desarrollo rural

\section{INTRODUÇÃO}

O trabalho, ao longo da história da humanidade, tem sido caracterizado por processos produtivos, que vão desde aqueles próprios das necessidades de subsistência e manutenção da vida, aos determinados pelo modelo social, político e econômico em vigência. Tais processos produtivos se estabeleceram em diferentes épocas, cenários e territórios, a depender da cultura histórica socialmente instituída, seja pelas famílias e comunidades, seja pela conjuntura dos governos e mercados, gerando, assim, demandas específicas.

Com o Capitalismo, os processos de reestruturação produtiva (ações mais voltadas à reorientação no processo da produção e traduzidas por meio de mudanças e suas consequências nos agentes produtivos) ocorreram nos diferentes setores da economia - primário (agricultura, pecuária e atividades extrativistas), secundário (indústria) e terciário (comércio e serviços). No entanto, a cultura da colheita da palha de carnaúba no Nordeste Brasileiro para a produção de cera (a folha, após manufaturada em cera in natura e industrializada, entra na composição de polidores, medicamentos, cosméticos, produtos de informática, dentre outros)

1 Universidade Estadual Vale do Acaraú (UVA), Sobral, Ceará, Brasil. 
e de artesanatos (chapéus, bolsas, dentre outros), além de esteiras para cavalos e cobertura de casas, tem se mantido há séculos como uma prática laborativa de modo artesanal, guardando especificidades de um processo de trabalho que vem sendo repassado de geração a geração de sertanejos.

A carnaúba ou carnaubeira, Copernicia prunifera (Miller) H.E. Moore, também denominada de "árvore da vida" pelos sertanejos, por suas múltiplas finalidades de aproveitamento, é uma palmeira nativa do semiárido Nordestino, comum nos vales dos rios, principalmente nos Estados do Ceará, Piauí e Rio Grande do Norte, sendo atualmente permitido somente o extrativismo de sua palha, apesar de seus troncos terem sido historicamente utilizados para construção de casas, currais, dentre outras edificações rurais (D'ALVA, 2004).

A carnaubeira tem uma importância econômica, social e ambiental. No âmbito econômico, segundo Costa e Gomes (2016, p. 4), "possui múltiplos usos, destacando-se a extração do pó cerífero e o aproveitamento das folhas no artesanato; no social, destaca-se pela geração de ocupação no meio rural e no ambiental, [...] além de colaborar com equilíbrio dos ecossistemas nos quais se insere". A principal riqueza da carnaúba "está na cera que recobre as folhas, principalmente as mais jovens, tornando-a internacionalmente conhecida como 'carnaubawax"' (SOUSA et al., 2015, p. 588).

Porém, no extrativismo da palha de carnaúba, em suas diversas fases (corte, transporte, secagem e a batedura, que é o início do beneficiamento), os trabalhadores estão expostos a muitos riscos, acidentes de trabalho e danos à saúde (D'ALVA, 2004; AGÊNCIA DE DESENVOLVIMENTO DO ESTADO DO CEARÁ [ADECE], 2009). E, considerando que o trabalho é um importante cenário para a exposição dos trabalhadores a riscos, doenças e agravos, a depender da magnitude e amplitude das atividades produtivas, estas podem influir diretamente no processo saúde-doença-cuidado-trabalho.

Destarte, o homem do campo, trabalhador e trabalhadora rural, mais precisamente do semiárido, vem enfrentando nos últimos anos longos períodos de estiagem, o que tem dificultado economicamente a vida destes sujeitos. As chuvas não são suficientes para garantir-Ihes fartura de alimentos na agricultura familiar, e nem a alimentação necessária para os animais no decorrer do ano; com isso, há a necessidade de uma atividade complementar para sua sobrevivência (CARVALHO; GOMES, 2006), sendo o extrativismo da palha de carnaúba rentável, mas que expõe o trabalhador a diversos riscos em suas diversas fases produtivas.

Tal situação nos instigou a adentrar no universo sertanejo e cartografar o processo produtivo dos trabalhadores rurais no extrativismo da palha de carnaúba.

\section{METODOLOGIA}

Pesquisa com método descritivo, do tipo estudo de caso, sob abordagem qualitativa, desenvolvida no município de Cariré, CE, durante o período de maio de 2016 a junho de 2017. Os estudos de caso, segundo Yin (2015), buscam explicar os vínculos causais em intervenções da vida real, que são complexas demais para as estratégias experimentais.

\subsection{Cenário do estudo}

A produção da cera de carnaúba no Brasil está concentrada em três estados nordestinos - Ceará, Piauí e Rio Grande do Norte, os quais, juntos, chegam a uma produção estimada em 30 
mil toneladas de pó ao ano. No Estado do Ceará, a carnaúba é encontrada em todo o território, com as maiores concentrações ocorrendo nos vales dos Rios Jaguaribe, Coreaú e Acaraú (D'ALVA, 2004). Dentre os municípios que se destacam na produção de cera, estão: Russas, Granja, Santana do Acaraú, Morada Nova, Aracati, Itarema e Cariré (IBGE, 2003), conforme mostra a Figura 1.

Figura 1 - Polos de Produção de Carnaúba no Ceará e a localização de Cariré.

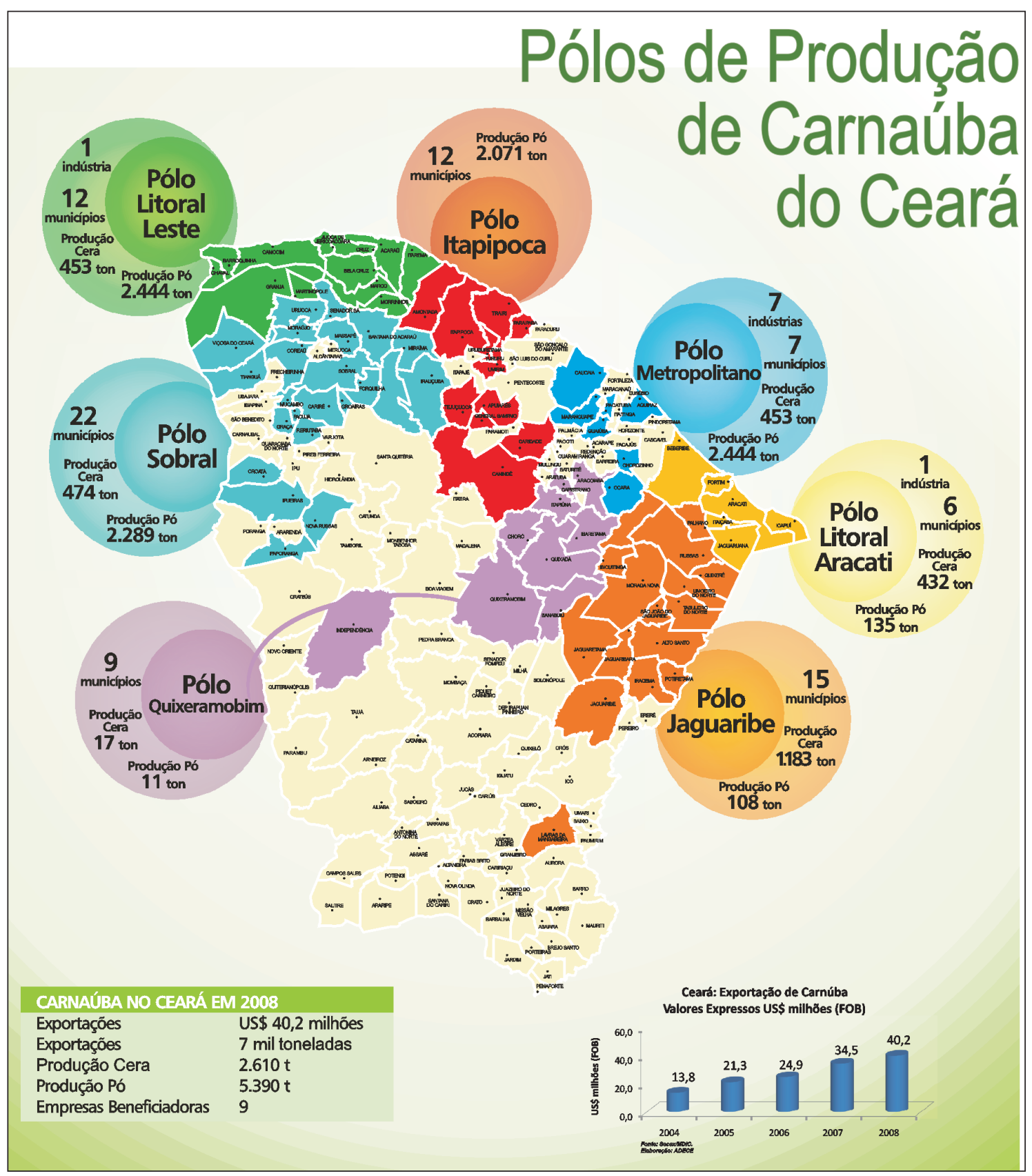

Fonte: ADECE (2009).

Cariré está entre os 22 municípios cearenses com comunidades produtivas de pó e cera de carnaúba (ADECE, 2009). Segundo dados do IBGE, o município de Cariré produziu 91 toneladas de cera de carnaúba no ano de 2015, com um valor de produção de $R \$ 1.579 .000,00$, além de 177 toneladas de pó de carnaúba, com um valor de $\mathrm{R} \$ 1.774 .000,00$ (IBGE, s.d.), estando entre os 10 maiores produtores do Estado. Cariré é um nome de origem indígena, que, segundo Pompeu, 
vem de cari (peixe) e ré (diferente); assim, Cariré significaria "peixe diferente" (MEDEIROS; DINIZ, 2004). O município citado está localizado na região Noroeste do Estado do Ceará, possuindo uma população estimada para o ano de 2016 de 18.652 habitantes, uma área territorial de 683 km², situado a $273 \mathrm{~km}$ da capital. Encontra-se inserido na zona do semiárido, precisamente dentro da depressão sertaneja, com bioma predominante da caatinga, também conhecido como mata branca (IBGE, s.d.).

\subsection{Sujeitos do estudo}

Os sujeitos do estudo são 18 trabalhadores rurais, moradores do Distrito de Tapuio e comunidade de Flores, situados nas proximidades do Rio Acaraú, além das comunidades de Muquém e Muquém de Dentro, região seca, porém com um acentuado carnaubal.

Todos os coletores do estudo são homens, com idades entre 21 e 65 anos (21 a 30 anos - quatro; 31 a 40 anos - seis; 41 a 50 anos - quatro; 51 a 60 anos - três; 61 e mais anos - um), que vivenciam juntos as jornadas de trabalho, independentemente de suas idades. Quanto à faixa etária, há o predomínio de adultos jovens. No tocante à raça/cor, 11 se autodeclararam como pardos e sete como brancos. Em relação à escolaridade, têm-se: um trabalhador rural analfabeto; 12 com ensino fundamental incompleto; três com ensino fundamental completo; e dois com ensino médio completo.

\subsection{Métodos, técnicas e procedimentos}

A coleta das informações foi realizada por meio de uma entrevista semiestruturada individual, seguida de observação. O roteiro da entrevista foi construído pelos próprios autores, contendo informações sobre o perfil sociodemográfico dos trabalhadores, perguntas específicas sobre o processo de trabalho individual em cada fase, os riscos que eles correm durante o extrativismo e os equipamentos de proteção individual utilizados. O roteiro de observação seguiu os itens da entrevista. No entanto, neste estudo, utilizou-se apenas o componente do processo de trabalho para descrever o processo produtivo da extração da palha.

As entrevistas ocorreram nos locais de coleta da palha de carnaúba e nas residências dos trabalhadores, a depender da disponibilidade e do agendamento prévio com estes. Ao início, foi explicado aos trabalhadores o objetivo e toda a trajetória da pesquisa. Após autorização dos sujeitos e assinatura do Termo de Consentimento Livre Esclarecido (TCLE), as falas foram gravadas, sendo posteriormente transcritas.

Concomitante à realização das entrevistas, foi realizada observação das diversas fases do processo produtivo, desde o corte da palha até a disposição destas para a secagem. A observação foi realizada em cinco momentos, sendo as informações registradas num diário de campo e, posteriormente, sistematizadas. Durante a observação, também foi construído um memorial fotográfico, com a anuência dos sujeitos, após assinarem o Termo de Autorização de Uso de Imagem.

Do material transcrito, fez-se uma leitura exaustiva, buscando compreender todos os sentidos das respostas e, assim, proceder a categorização, com base no referencial teórico proposto por Minayo (2010), a partir da técnica de análise de conteúdo, na fase de análise temática. Segundo a autora, diferentes são os tipos de análise de conteúdo: de expressão, das relações, de avaliação, de enunciação e categorial temática. Esta última compreende o tipo de técnica mais 
utilizada pela análise de conteúdo, que consiste em operações de desmembramento do texto em unidades (categorias), segundo os reagrupamentos analógicos, e propõe uma organização de informações de teor qualitativo.

A análise de conteúdo constitui um conjunto de técnicas de análise de comunicação visando a obter, por procedimentos sistemáticos e objetivos de descrição do conteúdo das mensagens, indicadores que permitam a inferência de conhecimentos relativos às condições de produção/ recepção destas mensagens (MINAYO, 2014). Após sistematização e análise temática das informações, emergiu a seguinte categoria: Processo Produtivo do Extrativismo da Palha da Carnaúba.

Com e após a análise de conteúdo, buscou-se cartografar o processo produtivo numa perspectiva não geográfica, mas das relações e interações subjetivas, para se conhecer a realidade em sua complexidade, com base no referencial de Deleuze e Guattari (1995). A cartografia é um método que, segundo Romagnoli (2009, p. 169), "não parte de um modelo pré-estabelecido, mas indaga o objeto de estudo a partir de uma fundamentação própria, afirmando uma diferença, em uma tentativa de reencontrar o conhecimento diante da complexidade".

\subsection{Aspectos éticos e legais da pesquisa}

Durante o desenvolvimento do estudo, foram observados os aspectos éticos e legais da pesquisa de acordo com a Resolução n. 466/2012 do Conselho Nacional de Saúde (CNS), que incorpora, sob a ótica do sujeito e das coletividades, os referenciais da bioética, tais como: autonomia, não maleficência, beneficência, justiça e equidade, dentre outros, e visa assegurar os direitos e deveres que dizem respeito aos participantes da pesquisa, à comunidade científica e ao Estado (BRASIL, 2012a).

Para preservar a identidade dos participantes do estudo, foi utilizado o termo "Trabalhador Rural" seguido de um numeral arábico. O protocolo da pesquisa foi submetido ao Comitê de Ética em Pesquisa (CEP) da Universidade Estadual Vale do Acaraú (UVA) sob CAE n. 47808515.4.0000.5053, sendo este aprovado pelo parecer n. 1.344.066. Ressalta-se que este artigo é um recorte da pesquisa intitulada "Doença, labor e trabalho no Semiárido Cearense: avaliação do perfil dos acidentes e da mortalidade por causas relacionadas ao trabalho na Zona Norte do Ceará".

\section{APRESENTAÇÃO E DISCUSSÃO DOS RESULTADOS: PROCESSO PRODUTIVO DO EXTRATIVISMO DA PALHA DE CARNAÚBA}

No município em estudo, existem diversas equipes que realizam o extrativismo anual da palha de carnaúba, sendo umas estruturadas em grupos maiores e outras com um número restrito de trabalhadores e limitado espaço territorial. Dentre estas, buscou-se estudar apenas as que atuam na parte mais significativa do território municipal, que abrange parte dos vales dos Rios Acaraú e Jaibaras, este último até as proximidades do Açude Taquara.

Cada equipe em estudo possui um arrendatário, que sai em busca dos proprietários das terras com carnaubais e, de forma peculiar, assim como se faz há séculos no sertão Nordestino, negocia o valor do carnaubal para o extrativismo da palha, efetuando o pagamento antecipado e fechando um pacto verbal para a coleta da palha somente no período de maior estiagem, entre os meses de julho e dezembro, em que as palmeiras estão mais frondosas e suas folhas apresentam uma maior concentração de camada cerosa, o que garantirá mais lucro 
para o arrendatário, que, muitas vezes, revende para o atravessador, antes de chegar ao final da cadeia produtiva.

O processo de arrendamento para o extrativismo da carnaúba se assemelha ao que descreve D’Alva (2004, p. 103). O contrato é firmado verbalmente, como também pode ser do tipo escrito, em que, mediante o pagamento, o arrendatário conquista o "direito de explorar temporariamente o carnaubal". Tal fato, segundo o autor, deve-se à concentrada estrutura fundiária do Ceará, que:

[...] determinou a forma dominante de organização do extrativismo da carnaúba. Enquanto um reduzido número de latifundiários dominou a maior parte das terras e carnaubais nativos do Estado, as áreas restantes foram divididas em um grande número de minifúndios, que não garantiam a reprodução social, o que obrigava as famílias minifundistas e sem-terra a buscar trabalho como parceiros ou assalariados nas grandes propriedades. (D'ALVA, 2004, p. 46).

Destaca-se que o extrativismo sustentável da palha de carnaúba, também denominado de conservação ambiental, é legalmente reconhecido, sendo recomendada a realização de somente um corte por ano e por carnaubal da palha "madura" ou daquelas que estão há mais de um ano sem cortes, tempo necessário para a recomposição da copa da árvore. O termo "palha madura" refere-se à árvore que passou por um período de recomposição da copa e da saída de novos olhos (palhas imberbes). No entanto, não podem ser retirados todos os pecíolos, tendo de ser mantido o "olho vela", e nem cortado o caule para a utilização da madeira. A retirada do "olho vela" leva à morte da árvore (BRASIL, 2012b; 2014; D’ALVA, 2004). O Ministério da Agricultura, Pecuária e Abastecimento, por meio da Secretaria de Desenvolvimento Agropecuário e Cooperativismo, recomenda um conjunto de boas práticas de manejo direcionadas ao extrativismo sustentável da palmeira carnaúba, que deve seguir as seguintes fases: diagnóstico (ou pré-exploratória); coleta (exploração) e pós-coleta (pós-exploratória); manutenção e proteção dos carnaubais e monitoramento (BRASIL, 2012b).

Quanto à tipologia das folhas da carnaubeira na linguagem do sertanejo, de acordo com D’Alva (2004), esta apresenta diversas denominações a depender da fase de seu ciclo de vida, que são: os olhos - o broto das palhas ainda fechadas; as folhas verdes medianas ou bandeiras; as folhas verdes maduras - as palhas; e as folhas secas, também denominadas de palhas-bravas. No campo deste estudo, pode-se observar que os coletores classificam as folhas da carnaubeira em apenas duas denominações: os olhos e a folha verde aberta de "palha-brava", conforme apresentado na Figura 2. 
Figura 2 - Tipologia das palhas de carnaubeira, Copernicia prunifera (Miller) H.E. Moore

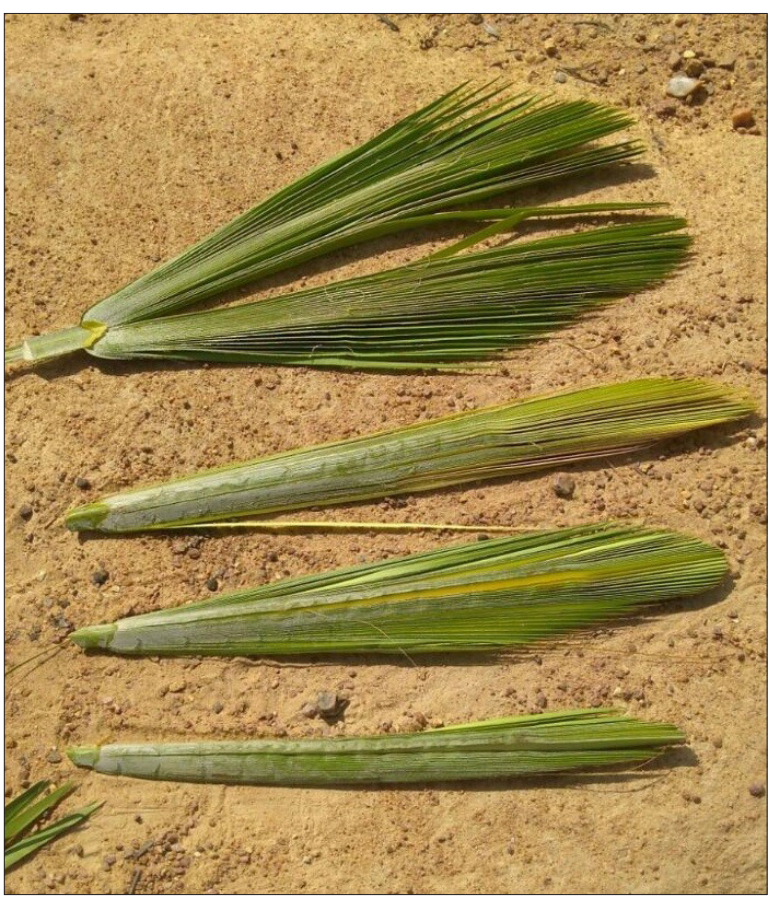

Fonte: Acervo pessoal dos autores.

Após o arrendamento dos carnaubais, cada arrendatário organiza uma equipe de trabalhadores rurais para efetuar o extrativismo - coleta das folhas (olhos e a "palha-brava"), transporte e secagem. Os trabalhadores são contratados de modo verbal, para a prestação de serviço, sendo estes pagos ao final de cada semana de trabalho, por diária trabalhada. A jornada de trabalho diária se inicia às cinco horas da manhã e se estende até 11 horas, perfazendo um total de seis horas corridas de trabalho diário.

Apesar de os trabalhadores serem contratados como diaristas, corroboramos com a Organização Internacional do Trabalho (OIT, 2005, p. 12) ao afirmar que os "empregadores têm o dever de proporcionar e manter os lugares de trabalho, as instalações, as ferramentas e outros equipamentos de trabalho em boas condições de segurança e saúde", já que estes, sem exceção, estão envoltos a riscos ocupacionais do tipo físico, químico, biológico, ergonômico e de acidentes, a exemplo: da exposição à luz solar e ao calor excessivo; à poeira do pó cerífero da palha; de picadas e mordeduras por animais peçonhentos; esforço físico intenso, associado ao ritmo excessivo de trabalho. Tais riscos influem diretamente no processo saúde-doença-cuidado-trabalho desses trabalhadores.

Dentre os trabalhadores contratados, estes se subdividem em algumas categorias, que são: o derrubador, também denominado de vareiro, que exerce como atividade produtiva a poda da palha da carnaubeira; o desenganchador, que tem a função de retirar as folhas que ficaram presas entre as árvores ou galhos; o aparador, que reduz o tamanho do pecíolo espinhoso para evitar acidentes e deixá-lo no tamanho padrão para o transporte. Em seguida, outro trabalhador as organiza em feixes, de modo que o comboieiro as transporta para o lastro. Por fim, o lastreiro, que é responsável por estender a palha em um campo aberto e limpo, para o processo de secagem (algo em torno de quatro dias para os olhos da palha e oito dias para a "palha-brava"), junta-as, 
selecionando por tamanho e separando as que serão trituradas na máquina. No momento de trituração da palha, também se podem agregar os trabalhadores que participaram das fases anteriores do processo de extrativismo, levando-os a riscos físicos, a exemplos dos ruídos, e de acidentes, por trabalhar com máquinas sem proteção (ver Figura 3).

O processo produtivo do extrativismo da palha de carnaúba está sistematizado nas Figuras 3 e 4.

Figura 3 - Fases do processo produtivo do extrativismo da palha de carnaubeira

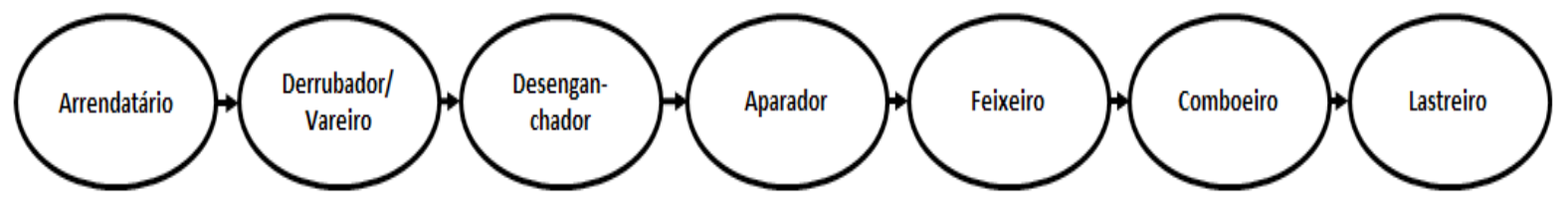

Fonte: Acervo pessoal dos autores.

O pó cerífero da palha é extraído somente após triturá-la na máquina, sendo este disposto em uma espécie de lona estirada no chão e, posteriormente, armazenado em sacos para ser vendido aos atravessadores para fabricarem a cera. A palha triturada, denominada popularmente de "bagana", tem valor significativo para os produtores rurais, pois serve como adubo no solo a ser plantada a cultura de milho e feijão no ano seguinte.

Figura 4 - Memorial fotográfico do processo produtivo do extrativismo da palha de carnaubeira
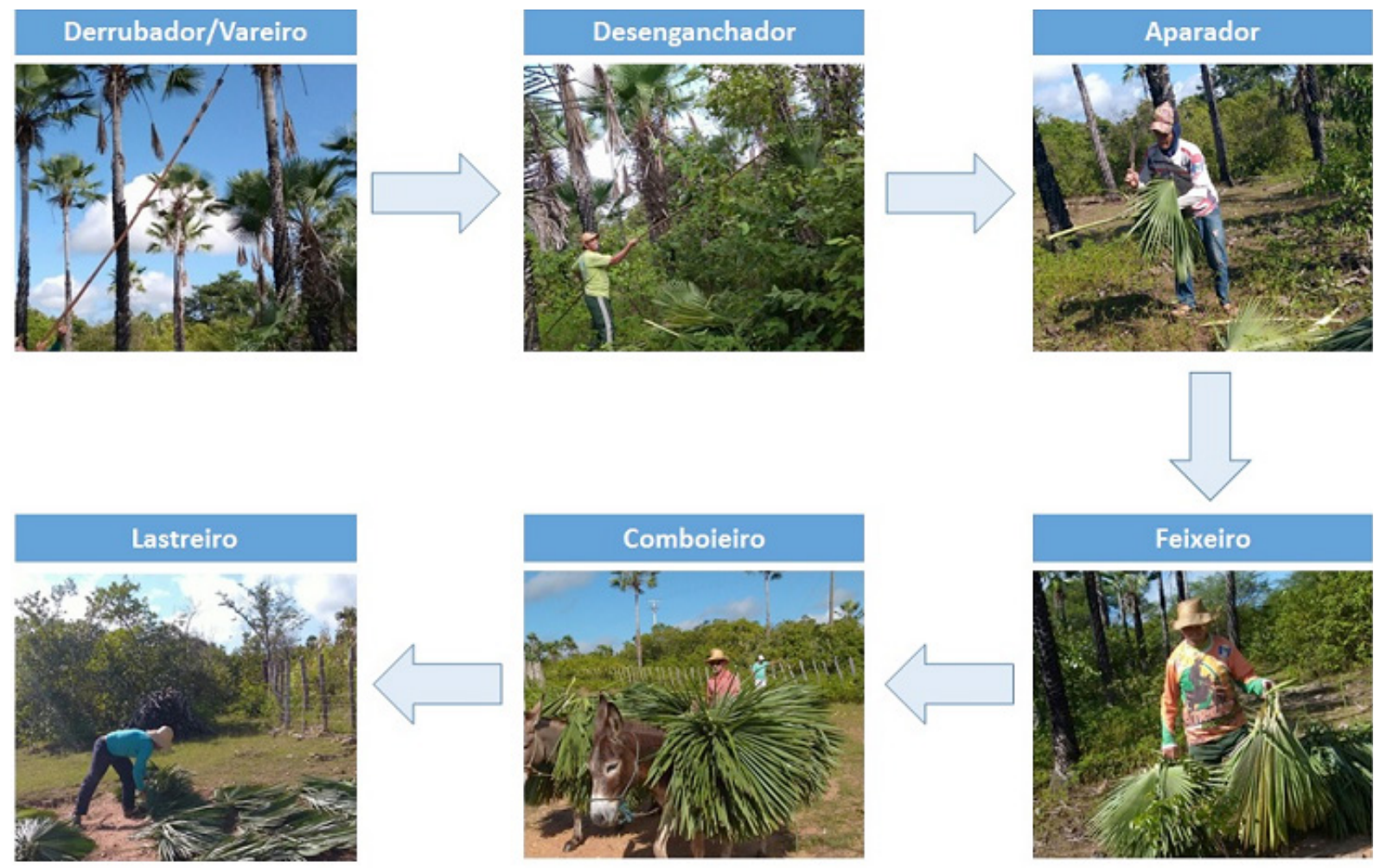

Fonte: Acervo pessoal dos autores. 
Existe ainda outra forma de extrair o pó da palha, feito por meio da riscagem, que é um procedimento realizado por mulheres, denominadas de "riscadeiras". Estas, com auxílio de uma faca pequena, fazem cortes na palha, separando a camada superficial do restante desta para a obtenção do pó. Este processo é feito nos olhos das palhas alta e "meiona", que são vendidas para a fabricação de chapéus e confecção de outros artesanatos, atividades produtivas de extrema importância econômica para complementar a renda do sertanejo e cultura local.

Carvalho (2008) afirma que o processo produtivo da palha de carnaubeira constitui uma atividade em que há especialidade de cada um dos trabalhadores que a executam, dependendo, essencialmente, das habilidades destes. Segundo Carvalho e Gomes (2006), o extrativismo da palha de carnaúba é uma atividade altamente braçal, em que o grau de instrução dos trabaIhadores não influencia no rendimento do pó, tornando, assim, um trabalho não qualificado e exigindo do trabalhador, portanto, somente esforço físico e habilidade para executá-lo.

Costa e Gomes (2016) citam ainda que diversas pesquisas comprovaram ser o extrativismo da carnaubeira uma fonte de emprego no campo, o que tem sido reconhecido não somente pelo Banco do Nordeste do Brasil (BNB), que tem liberado recursos financeiros para tal atividade produtiva, como também pelos diversos segmentos da cadeia produtiva da cera, desde os arrendatários até a indústria manufatureira.

\section{CONSIDERAÇÕES FINAIS}

A importância da extração da palha da carnaúba para os trabalhadores rurais e suas famílias, por ser uma atividade que lhes garante subsistência durante um determinado período do ano, em que já não há mais atividades na lavoura, submete-os a um trabalho que lhes coloca numa condição social e sanitária de vulnerabilidade.

O extrativismo da palha de carnaúba é uma atividade que envolve uma equipe de trabaIhadores rurais que exercem diferentes funções, mas cada atividade do processo produtivo se interliga uma a outra. No entanto, o extrativismo da palha de carnaúba expõe os trabalhadores a riscos, doenças e agravos nas diversas fases do processo produtivo, pelas condições insalubres a que estão submetidos em meio à caatinga e pelo não uso de equipamentos de proteção individual, o que pode influir diretamente no processo saúde-doença-cuidado-trabalho.

Apesar da renda proporcionada ao sertanejo durante o período de maior estiagem, alguns aspectos ainda são característicos no processo produtivo de extração da palha de carnaúba e merecem ser mais bem analisados e estudados. São eles:

- Os trabalhadores/famílias envolvidos na extração da palha quase sempre são contratados por terceiros (arrendatário), de modo precário, sem direitos e garantias trabalhistas, e, em caso de acidentes de trabalho, não terão direitos previdenciários garantidos. O arrendatário, em alguns casos, está submetido às mesmas condições precárias dos demais e ainda atua no extrativismo;

- O trabalhador rural no extrativismo da palha é pago por dia trabalhado, e não com um salário mensal em carteira de trabalho;

- Neste estudo, o gênero masculino predomina na extração. Mas há casos em que famílias inteiras de trabalhadoras e trabalhadores rurais se envolvem no extrativismo, com segmentação de trabalho por fases, deixando o braçal pesado para os homens, quase sempre;

- Os trabalhadores não estão vinculados à estrutura associativista. Apenas alguns trabaIhadores, principalmente os com idade próxima ao período de aposentadoria, estão vinculados ao Sindicato dos Trabalhadores e Trabalhadoras Rurais local. 
Contudo percebe-se a necessidade dos trabalhadores rurais envolvidos no extrativismo da palha, como os demais do segmento, de proteção social por meio de políticas públicas trabalhistas, de Assistência Social e de Saúde.

\section{REFERÊNCIAS}

AGÊNCIA DE DESENVOLVIMENTO DO ESTAdo dO CEARÁ (ADECE). Câmara Setorial da Carnaúba. A carnaúba: preservação e sustentabilidade. Fortaleza: Câmara Setorial da Carnaúba, 2009. 40 p. Disponível em: http://www.sfiec.org.br/portalv2/sites/sindicarnauba/files/Brochura_Carna\%C3\%BAba2.pdf. Acesso em: 8 maio 2017.

BRASIL. Ministério da Agricultura, Pecuária e Abastecimento. Secretaria de Desenvolvimento Agropecuário e Cooperativismo. Carnaúba, Copernicia prunifera. Brasília: MAPA/ACS, 2014. 43 p. (Série: Cadernos de Boas Práticas para o Extrativismo Sustentável Orgânico).

BRASIL. Conselho Nacional da Saúde (CNS). Resolução n. 466, de 12 de dezembro de 2012. Brasília, DF: CNS/Ministério da Saúde, 2012. Disponível em: http://conselho.saude.gov.br/resolucoes/2012/Reso466. pdf. Acesso em: 12 maio 2017.

BRASIL. Ministério da Agricultura, Pecuária e Abastecimento. Secretaria de Desenvolvimento Agropecuário e Cooperativismo. Carnaúba: Copernicia prunifera. Brasília: MAPA/ACS, 2012b. 33 p. (Série: Boas práticas de manejo para o extrativismo sustentável orgânico).

CARVALHO, J. N. F. Pobreza e tecnologias sociais no extrativismo da carnaúba. 2008. 100 f. Dissertação (Mestrado em Desenvolvimento e Meio Ambiente) - Universidade Federal do Piauí (UFPI), Teresina, 2008. Disponível em: http://www.leg.ufpi.br/subsiteFiles/mestambiente/arquivos/files/ Disserta\%C3\%A7\%C3\%A30\%20Final\%20Jos\%C3\%A9\%20Natanael.pdf. Acesso em: 16 jun. 2017.

CARVALHO, J. N. F.; GOMES, J. M. A. Indicadores socioeconômicos dos trabalhadores da extração do pó cerífero da carnaúba. In: GOMES, J. M. A.; SANTOS, K. B.; SILVA, M. S. (Org.). Cadeia produtiva da cera de carnaúba: diagnóstico e cenários. Teresina, PI: EDUFPI, 2006. p. 119-29.

COSTA, V. L. S.; GOMES, J. M. A. Crédito e conservação ambiental no extrativismo da carnaúba (Copernicia prunifera (Mill.) H. E. Moore) no nordeste brasileiro no período de 2007 a 2012. Interações, Campo Grande, MS, v. 17, n. 1, p. 4-14, jan./mar. 2016. DOI http://dx.doi.org/10.20435/1518-70122016101. Disponível em: http://www.scielo.br/scielo.php?script=sci_arttext\&pid=S1518-70122016000100004\&lng=en\&nr m=iso. Acesso em: 10 mar. 2018.

D'ALVA, O. A. O extrativismo da carnaúba no Ceará. 2004. 186 f. Dissertação (Mestrado em Desenvolvimento e Meio Ambiente) - Universidade Federal do Ceará (UFC), Fortaleza, 2004. Disponível em: http://www. repositorio.ufc.br/handle/riufc/16166. Acesso em: 2 jun. 2017.

DELEUZE, G.; GUATTARI, F. Mil platôs - Capitalismo e esquizofrenia. Tradução Aurélio Guerra Neto e Célia Pinto Costa. Rio de Janeiro: Ed. 34, 1995. v. 1, 94 p. (Coleção TRANS).

INSTITUTO BRASILEIRO DE GEOGRAFIA E ESTATÍSTICA (IBGE). Cidades@. Ceará - Cariré: Informações Completas. [s.d.]. Disponível em: http://cidades.ibge.gov.br/xtras/perfil.php?lang=\&codmun=230310\&s earch=| | infogr\%E1ficos:-informa\%E7\%F5es-completas. Acesso em: 5 jun. 2017.

INSTITUTO BRASILEIRO DE GEOGRAFIA E ESTATÍSTICA (IBGE). Produção da extração vegetal e da silvicultura. Rio de Janeiro: IBGE, 2003. v. 18. Disponível em: https://www.ibge.gov.br/home/estatistica/economia/ pevs/2003/default.shtm. Acesso em: 20 maio 2017. 
MEDEIROS, M. A.; DINIZ, A. S. A quebra do sistema produtivo do semi-árido: O caso do algodão em Cariré (CE). Revista da Casa da Geografia de Sobral (RCGS), v. 6, n. 1, p. 2004. Disponível em: http://www.uvanet. br/rcgs/index.php/RCGS/article/view/123>Citado em: 20 de março de 2017.

MINAYO, M. C. S. O desafio do conhecimento: pesquisa qualitativa em saúde. 14. ed. São Paulo: HUCITEC, 2014.

MINAYO, M. C. S. (Org.). Pesquisa social: teoria, método e criatividade. 29. ed. Petrópolis, RJ: Vozes, 2010.

ORGANIZAÇÃO INTERNACIONAL DO TRABALHO (OIT). Programa de Actividades Sectoriales. Repertorio de recomendaciones prácticas sobre seguridad y salud en la agricultura. Ginebra $(\mathrm{CH})$ : Oficina Internacional del Trabajo, 2005. Disponível em: http://www.ilo.org/wcmsp5/groups/public/---ed_protect/---protrav/--safework/documents/normativeinstrument/wcms_112442.pdf. Acesso em: 18 jun. 2017.

ROMAGNOLI, R. C. A cartografia e a relação pesquisa e vida. Psicologia \& Sociedade, Florianópolis, v. 21, n. 2, p. 166-73, maio/ago. 2009. DOI http://dx.doi.org/10.1590/S0102-71822009000200003. Disponível em: http://www.scielo.br/scielo.php?script=sci_arttext\&pid=S0102-71822009000200003\&lng=en\&nrm =iso. Acesso em: 6 jun. 2018.

SOUSA, R. F.; SILVA, R. A. R.; ROCHA, T. G. F.; SANTANA, J. A. S.; VIEIRA, F. A. Etnoecologia e etnobotânica da palmeira carnaúba no semiárido brasileiro. CERNE, Lavras, MG, v. 21, n. 4, p. 587-94, out./dez. 2015. DOI http://dx.doi.org/10.1590/01047760201521041764. Disponível em: http://www.scielo.br/scielo. php?script=sci_arttext\&pid=S0104-77602015000400587\&lng=en\&nrm=iso. Acesso em: 10 mar. 2018.

YIN, R. K. Estudo de caso: planejamento e métodos. 5. ed. Tradução Daniel Grassi. Porto Alegre: Bookman, 2015.

Sobre os autores:

Francisco Rosemiro Guimarães Ximenes Neto: Doutor em Ciências. Mestre em Saúde Pública. Especialista em Saúde Coletiva. Enfermeiro sanitarista. Professor adjunto da Graduação em Enfermagem e do Mestrado Profissional em Saúde da Família da Universidade Estadual Vale do Acaraú (UVA), Sobral, CE. Professor visitante do Mestrado Acadêmico em Saúde da Família da Universidade Federal do Ceará (UFC). E-mail: rosemironeto@gmail.com, Orcid: http://orcid.org/0000-0002-7905-9990

Francisca Sandra da Ponte: Enfermeiro pela Universidade Estadual Vale do Acaraú (UVA), Sobral, CE. Hospital Municipal de Cariré, Secretaria da Saúde de Cariré, CE, Brasil. E-mail: sandraponte23@hotmail.com, Orcid: http://orcid.org/0000-0002-4260-9573

Petrônio Emanuel Timbó Braga: Pós-doutorado pelo Departamento de Biologia na Universidade de Évora-UEVORA, Portugal. Doutor e mestre em Agronomia/Fitotecnia pela Universidade Federal do Ceará (UFC). Engenheiro agrônomo. Professor Associado da Universidade Estadual Vale do Acaraú (UVA). Conselheiro titular do Conselho Estadual do Meio Ambiente da Secretaria Estadual do Meio Ambiente (COEMA/SEMACE). Consultor ad hoc: PROEXT/MEC-2009. Membro integrante do Banco de Avaliadores do Sistema Nacional de Avaliação da Educação Superior-BASis; consultor ad hoc de revistas científicas; líder do Grupo de Pesquisa Artropodofauna do Semiárido Nordestino; membro do Colegiado do Curso de Ciências Biológicas (Licenciatura e Bacharelado).E-mail: timbobraga@hotmail.com, Orcid: http://orcid.org/0000-0003-4091-3077 
